\title{
The occurrence of radiostrontium in foodstuffs
}

\author{
By J. Hawthorn, Department of Food Science, Royal College of Science and \\ Technology, Glasgow
}

\section{Introduction}

Information on radiostrontium levels in food is available from Japan, Russia, Canada, the United States and the United Kingdom although the greatest volume of published data has come from the United Kingdom and the United States. This paper will deal mainly with information applied to the United Kingdom although it would be expected that other nations living on similar diets would show the same patterns of distribution through the various foodstuffs.

Radiostrontium reaches the human skeleton by three routes. It may be absorbed by the lungs from suspended particles in air, or it may be consumed in drinking water, or in food. It appears that absorption through the lungs is likely to be small and that drinking water may or may not contribute significantly to the total intake depending on the source of supply (Bryant, Chamberlain, Morgan \& Spicer, 1957). Thus, though foodstuffs are believed to make the most important contribution to absorption of radiostrontium it must not be assumed that they are the sole source.

Man's diet is derived ultimately from crops, which are either consumed directly or after conversion into animal products. In the process of absorption, animal digestive systems discriminate against strontium in favour of calcium (Comar, Russell $\&$ Wasserman, 1957). For example, a cow consuming a diet containing $60 \mu \mu \mathrm{c}{ }^{90} \mathrm{Sr} / \mathrm{g}$ calcium will produce milk containing about 10 $\mu \mu \mathrm{c}$ of the isotope/g calcium. There is also evidence that in human digestive processes there is discrimination against strontium and in favour of calcium which is preferentially taken up for deposition in the bone (Bryant, Chamberlain, Spicer \& Webb, 1958; Comar, Wasserman, Ullberg \& Andrews, 1957), although the ratios found have varied in different experiments. At the worst, a subject whose sole source of calcium is milk containing I0 $\mu \mu \mathrm{c}{ }^{90} \mathrm{Sr} / \mathrm{g}$ calcium will lay down $5 \mu \mu \mathrm{c}$ of the isotope/g new bone calcium and at the best perhaps $2.5 \mu \mu \mathrm{c}$. From these considerations it is clear that nations deriving their dietary calcium mainly from animal sources are more advantageously placed with regard to uptake of radiostrontium than those largely dependent on cereals, animals acting as an intermediate biological filter. Similarly, a vegetarian may absorb twice as much ${ }^{90} \mathrm{Sr}$ as would be absorbed from a mixed diet (Kulp \& Slakter, 1958).

\section{${ }^{80} \mathrm{Sr}$ in the British diet}

Table $\mathrm{x}$, compiled by Bryant et al. (1958), shows the mean daily intake of ${ }^{90} \mathrm{Sr}$ from various foods along with the corresponding figures for calcium.

Very recently, Kulp \& Slakter (1958) have reported values for foodstuffs in the United States and conclude that the ${ }^{90} \mathrm{Sr}$ content in the diet of the average United States citizen in 1957 was about $6.5 \mu \mu \mathrm{c} / \mathrm{g}$ calcium. The importance of milk in these dietary patterns calls for comment. There are regional variations in the ${ }^{90} \mathrm{Sr}$ levels 
Table I. Mean daily intake/head of calcium and ${ }^{90} \mathrm{Sr}$ from various foods in the United Kingdom (from Bryant et al. 1958)

$\quad$ Food
Milk and milk products
Flour and foods baked from it
Potatoes and carrots
Cabbage, lettuce, peas and beans
Other vegetables and fruit
Other cereals
Meat
Eggs
Fish
Other foods
Total

$\begin{array}{cl}\begin{array}{c}\text { Calcium } \\ (\mathrm{mg})\end{array} & \begin{array}{l}90 \mathrm{Sr} \\ (\mu \mu \mathrm{c})\end{array} \\ 667 & 3.64 \\ 332 & 0.66 \\ 25 & 0.51 \\ 21 & 0.24 \\ 58 & 0.87 \\ 11 & 0.11 \\ 27 & 0.40 \\ 24 & 0.05 \\ 19 & 0.02 \\ 15 & 0.15 \\ & \\ \text { I } 199 & 6.65\end{array}$

in milk, depending on factors such as the calcium status of the pasture on which the animals are grazing and the average rainfall. In general, hill pastures will be expected to contain higher levels than lowland pastures. There may be seasonal fluctuations depending on whether animals are at grass or on winter feed and it is also probable that a given patch of pasture may show variations in radiostrontium activity with different rates of growth (Hawthorn, Stanwix \& Duckworth, 1958). It is therefore interesting to compare maximum and minimum levels in milk at different times.

Table $2 * .{ }^{90} \mathrm{Sr}$ levels ( $\mu \mu \mathrm{c} / \mathrm{g}$ calcium) in milk: values for the United Kingdom and mean values for the 'world'

$\begin{array}{lcccc}\text { United Kingdom } \\ \text { Year } & \text { No. of samples } & \text { Maximum } & \text { Minimum } & \text { 'World' } \\ 1954 & - & - & - & 1 \cdot 2 \\ 1955 & 9 & 5 \cdot 8 & 1 \cdot 7 & 3 \cdot 7 \\ 1956 & 23 & 10 \cdot 3 & 2 \cdot 9 & 5 \cdot 1 \\ 1957 & 49 & 33 & 3 \cdot 4 & 6 \cdot 7\end{array}$

*Compiled from data published by Bryant et al. $(1956,1957,1958)$ and by United Nations Scientific Committee on the Effects of Atomic Radiation (1958). The 'world' values were obtained by simple averaging of data from different countries published in this last report.

The commercial practice of bulking milk doubtless irons out some of the fluctuations recorded, but in hill areas milk levels would be expected to exceed the national average by a factor of about 3 (calculated by me from data of Bryant et al. (1958) on milk from hill farms). If this figure is applied to values in Table $I$, it seems probable that the mean daily total intake of ${ }^{90} \mathrm{Sr}$ by people deriving their milk wholly from hill pasture may be as high as $13.9 \mu \mu \mathrm{c} *$, or double that in other parts of the country. It is therefore desirable to obtain further data on milk in the Scottish Highlands and in Wales in relation to the ${ }^{90} \mathrm{Sr}$ levels in human bone in these regions.

The figures given for flour and bread in Table $\mathbf{I}$ are influenced by the statutory addition of mineral calcium carbonate to flour. They are based on four samples of flour whose mean ${ }^{90} \mathrm{Sr}$ level was $2 \cdot 0 \mu \mu \mathrm{c} / \mathrm{g}$ calcium. On the assumption that calcium

$*_{3} \times 3.64$ (from milk) +3.0 r (from other foods) $=13.93 \mu \mu \mathrm{c}$. 
had been added to the flour at the standard rate of $125 \mathrm{mg} / \mathrm{I} 00 \mathrm{~g}$, the activity in the flour before treatment would average $10.4 \mu \mu \mathrm{c} / \mathrm{g}$ calcium. Thus, in so far as it acts as a diluent to absorbed ${ }^{90} \mathrm{Sr}$, added calcium carbonate serves as a distinct, if small, protective factor. It is interesting to note that Klechkovsky \& Guliakin (1957) found, in tracer experiments, that most of the radiostrontium activity entering the wheat plant was concentrated in the leaf, root and stem rather than in the grain, a finding confirmed and extended to other cereals by Duckworth (1958) in our own laboratory.

With the exception of those for milk, the values given in Table I are based on small numbers of samples, but the fact that it has been possible to compile a table of this sort for the first time in the United Kingdom is a most useful advance in our knowledge of this subject.

\section{Effect of preparation and cooking on radiostrontium activity}

The fact that most foods in the United Kingdom are subjected to processing operations of various sorts between the farm gate and the consumer raises the question as to whether any of these operations influences the intake of radiostrontium. The effect of cooking comes first to mind, but blanching operations in canning and quick-freezing, the peeling of vegetables and the selective extraction of endosperm during the milling of wheat may possibly contribute to reducing the actual amount consumed. From lack of data, answers to these questions must be largely speculative, but some indications of probable effects can be given.

With leafy vegetables it is reasonable to suppose that, in addition to root uptake, the outermost parts of the plant will receive fallout directly and it may either be absorbed or lie on the leaf surface. It is also well known that potato peelings tend to have a higher calcium content than the corresponding potato flesh, and radiostrontium values might well be reflected in such differences. The opportunity is therefore taken to report some observations from our own laboratory on the effect of domestic preparation on radiostrontium levels.

Radiochemical analysis of biological materials for ${ }^{90} \mathrm{Sr}$ is a lengthy process extending over 3 or 4 weeks and depends on the ultimate isolation of the yttrium daughter isotope and the measurement of its activity, which is then related to the ${ }^{90} \mathrm{Sr}$ present (Bryant et al. I956). This procedure specifically measures ${ }^{90} \mathrm{Sr}$ and is necessary to distinguish it from the less harmful ${ }^{89} \mathrm{Sr}$, but where the interest of an experiment lies in ratios (for example, percentage losses in cooking or in preparation of vegetables) it may often be sufficient to determine the total strontium activity. In the experiments described here this procedure was adopted. The analytical procedure is as follows.

Potato, cabbage, brussels sprouts and turnip have been examined. Root vegetables are first washed to remove adhering soil and then peeled, and the greens are trimmed in the usual way for cooking. The outer and edible portions are then analysed separately. The material is dried at $80^{\circ}$ and then ashed in silica dishes at $600^{\circ}$. Normally I-2 kg raw material are ashed for each assay. A suitable portion of ash (normally $5 \mathrm{~g}$, but more or less depending on the expected activity) is weighed, moistened with conc. $\mathrm{HCl}$ and evaporated to dryness at least twice. To the residue is added $2 \cdot 5 \mathrm{ml}$. strontium-carrier solution (Io $\mathrm{mg} \mathrm{Sr} / \mathrm{ml}$.) followed by $35 \mathrm{ml}$. water. Fuming 
nitric acid ( $15 \mathrm{ml}$, sp. gr. $\mathrm{I}_{5} \mathrm{I}$ ) is added and the mixture is stirred until the sample is dissolved. Any insoluble material such as silica or carbon particles is filtered off through acid-resisting paper and a further $50 \mathrm{ml}$. of fuming nitric acid are added to the clear solution. The material is then left in a refrigerator for $\mathrm{I} h$ to permit crystallization of the strontium nitrate. The crystals are filtered off on glass-fibre filter discs (H. Reeve Angel and Co. Ltd), dissolved in $25 \mathrm{ml}$. water and recrystallized by a further addition of fuming nitric acid. Crystallization is always carried out at least twice, but where interference from extraneous material is suspected, it may be repeated more often. The strontium nitrate is finally dissolved in $25 \mathrm{ml}$. water, precipitated as carbonate with ammonia and ammonium carbonate, filtered on to $25 \mathrm{~mm}$ glass-fibre filter discs, dried and weighed to permit a correction for yield on crystallization, mounted on $I$ in. aluminium planchets and counted on an end-window Geiger counter standardized with ${ }^{89} \mathrm{Sr}$, it being convenient for comparative purposes to express results in $\mu \mu \mathrm{c}$. This simplified procedure saves a great deal of time and we consider it adequate for this particular purpose. The results are shown in Table 3, and it is clear that analytical results based on whole vegetables may be misleading.

Table 3. Effect of household preparation of vegetables on their radiostrontium* activity

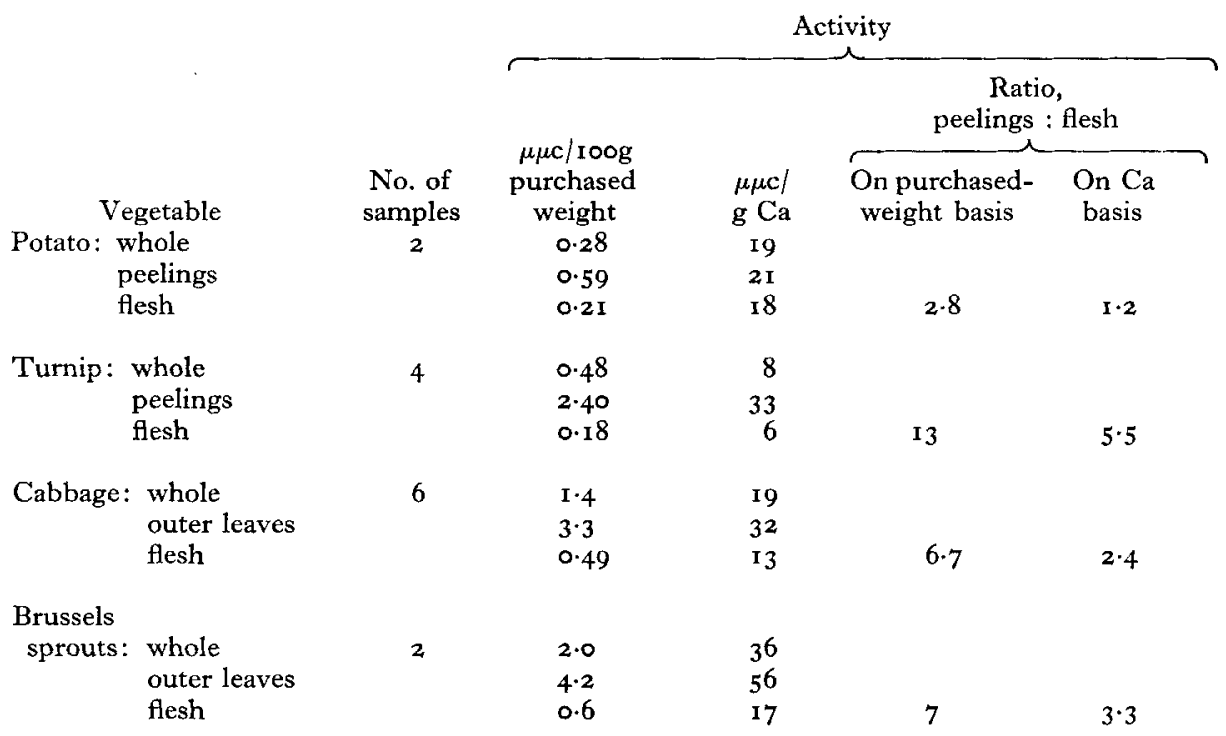

*The term radiostrontium is used to include all activities measured by the method described in the text. This method is not specific for strontium isotopes, and precipitates may have included some activity from other isotopes with chemical characteristics similar to those of strontium.

American figures for ${ }^{90} \mathrm{Sr}$ in vegetables (Kulp \& Slakter, 1958) were obtained with frozen food that had presumably been subject to normal processes of preparation. British samples (Bryant et al. 1958) were also prepared as for cooking, the outer leaves of cabbage being discarded, but the potatoes were not peeled, with the exception of two samples in which the peel was analysed separately. These two samples 
were analysed specifically for ${ }^{90} \mathrm{Sr}$ and gave a mean ratio of activity, peel to flesh, of 2.2 on a dry-weight basis, as against 2.8 on the wet-weight basis of Table 3 ; on a calcium basis, the ratio was 0.77 as compared with $1 \cdot 2$. Because of the small number of samples available for comparison, and of differences in analytical methods and methods of peeling, the values may be taken to be in fair agreement. All the results show, on a 'weight as purchased' basis, that the parts of the plants discarded in normal preparation are of higher activity than the parts consumed. This pattern has been confirmed by tracer studies in which plants were fed on ${ }^{89} \mathrm{Sr}$ and autoradiographs prepared from sections.

Little attention has been paid to the effect of cooking on strontium levels in foods, and the problem is being investigated in our own laboratories although it is too early yet to come to any conclusions. However, it would be reasonable to expect some further loss of activity due, with vegetables, to extraction by cooking fluids, provided that the cooking water is itself free from activity. Thus one may conclude that in the human diet there are a number of factors which taken together contribute to a useful degree of protection from fallout. Of these, the ability of the cow to discriminate against strontium in milk production is the most significant.

\section{REFERENCES}

Bryant, F. J., Chamberlain, A. C., Morgan, A. \& Spicer, G. S. (1956). Radiostrontium Fallout in Biological Materials in Britain. Atomic Energy Research Establishment, Harwell. HP/R2056.

Bryant, F. J., Chamberlain, A. C., Morgan, A. \& Spicer, G. S. (1957). Radiostrontium in Soil, Grass, Milk and Bone in the United Kingdom. Atomic Energy Research Establishment, Harwell. HP/R2353

Bryant, F. J., Chamberlain, A. C., Spicer, G. S. \& Webb, M. S. W. (1958). Brit. med. F. i, 137г.

Comar, C. L., Russell, R. S. \& Wasserman, R. H. (1957). Science, 126, 485.

Comar, C. L., Wasserman, R. H., Uliberg, S. \& Andrews, G. A. (1957). Proc. Soc. exp. Biol., N.Y., 95, 386.

Duckworth, R. B. (1958). Unpublished.

Hawthorn, J., Stanwix, P. R. \& Duckworth, R. B. (1958). Unpublished.

Klechkovsky, V. M. \& Guliakin, I. V. (1957). International Conference on Radioisotopes in Scientific Research, Paris. UNESCO/NS/RIC/I4I.

Kulp, J. L. \& Slakter, R. (1958). Science, 128, 85 .

United Nations Scientific Committee on the Effects of Atomic Radiation (1958). Report of the 13th Session, Suppl. no. $17\left(\mathrm{~A} / 3^{8} 38\right)$.

The following references, not mentioned in the text, contain further relevant information:

Anderson, E. C., Schuch, R. L., Fisher, W. R. \& Langham, W. (r957). Science, r25, 1273.

Anderson, E. C., Schuch, R. L., Fisher, W. R. \& Van Dilla, M. A. (1958). Science, 127, 283.

Booker, D. V., Bryant, F. J., Chadwick, R. C., Chamberlain, A. C. \& Morgan, A. (1956). Radiostrontium Fallout in Soil, Plant and Bone up to December, 1955. Atomic Energy Research Establishment, Harwell. HP/Mio8.

Bryant, F. J., Chamberlain, A. C., Morgan, A. \& Spicer, G. S. (1957). F. nucl. Energy, 6, 22.

Comar, C. L. \& Wasserman, R. H. (1957). International Conference on Radioisotopes in Scientific Research, Paris. UNESCO/NS/RIC/1 76 .

Eckelmann, W. R., Kulp, J. L. \& Schulert, A. R. (1958). Science, 127, 266.

Harley, J. H., Hardy, E. P., Welford, G. A., Whitney, I. B. \& Eisenbud, M. (1956). Summary of Analytical Results from the HASL Strontium Program to Fune, 1956. Report NYO-475I (Rev.) United States Atomic Energy Commission.

Harley, J. H., Hardy, E. P., Whitney, I. B. \& Eisenbud, M. (1957). Summary of Analytical Results from the HASL Strontium Program through fuly to December, 1956. Report NYO-4862 United States Atomic Energy Commission. 
Martin, R. P., Newbould, P. \& Russell, R. S. (1957). International Conference on Radioisotopes in Scientific Research, Paris. UNESCO/NS/RIC/175.

Newcombe, H. B. (1957). Science, 126, 549.

\title{
Nutritional hazards caused by radioactive contamination of foods
}

\author{
By G. B. S. Heath, Ministry of Agriculture, Fisheries and Food, \\ Veterinary Investigation Centre, Penrith
}

The hazards which may exist as a result of the contamination of herbage by radioactive material will depend upon the degree of contamination and the active isotope or isotopes concerned. It is proposed, therefore, to summarize briefly the way in which fallout from a bomb may affect a crop.

\section{Isotopes that may contaminate crops}

Fallout may be made up of a hundred or more active isotopes but only a few of them are likely to be harmful as crop contaminants.

Iodine. As ${ }^{131} \mathrm{~T}$, it will be a major hazard for a few weeks after fallout arrives. Chamberlain \& Chadwick (1953) showed that iodine gas is deposited on grass by diffusion. Chamberlain, Loutit, Martin \& Russell (1955) note that, in fresh fission products, the iodine hazard will be increased since the short-lived isotopes ${ }^{132} \mathrm{I}$, ${ }^{133} \mathrm{I}$, and ${ }^{135} \mathrm{I}$ will make a considerable contribution. The maximum permissible concentration on herbage is well below that needed for external radiation hazards (Parker, I950).

Caesium. Much has been heard about the possible effect of ${ }^{137} \mathrm{Cs}$ but it is difficult to assess the dangers that may be associated with this isotope. Ingested caesium is well absorbed and a high concentration develops in muscles (Hood \& Comar, I953). Thus, apart from possible damage to the health of animals, ingestion of ${ }^{137} \mathrm{Cs}$ may render the animal useless as a source of meat. On the other hand, caesium is not readily taken up from the soil by plants (Anderson, Schuch, Fisher \& Langham, 1957) and its biological half-life is fairly short-140 days in man and 20 days in cattle. It might be wise to regard ${ }^{137} \mathrm{Cs}$ as a hazard of unknown degree.

Strontium. There is no doubt whatever about the dangers associated with contamination of crops by ${ }^{89} \mathrm{Sr}$ and ${ }^{90} \mathrm{Sr}$. Lapp (1955) points out that radiostrontium (a) has a long half-life, (b) is born with a high fission yield, (c) because of its gaseous predecessor, diffuses throughout the fireball of a thermonuclear explosion and 'plates' upon the debris, (d) resembles calcium and is thus subject to uptake in biological systems and (e) is a bone-seeker and, because of it, its $\beta$-rays are of considerable biological significance. Lapp also stresses the fact that, weight for weight, ${ }^{89} \mathrm{Sr}$ is $\mathrm{I} 80$ times more radioactive than ${ }^{90} \mathrm{Sr}$; this higher activity is associated with its shorter half-life. From published figures, he calculates that a I0-megaton thermonuclear bomb might deposit $2-3 \mathrm{~g}$ radiostrontium/sq. mile, and this tiny weight of 18 (1) 5 